\title{
Impact of video information before unsedated upper gastrointestinal endoscopy on patient satisfaction and anxiety: a prospective randomized trial
}

\author{
Mahmut Arabul', Altay Kandemir ${ }^{1}$, Mustafa Celik ${ }^{1}$, Serkan Torun ${ }^{2}$, Yavuz Beyazit ${ }^{2}$, Emrah Alper ${ }^{1}$, Mehmet Camci ${ }^{1}$, \\ Belkis Ünsal ${ }^{1}$ \\ 1Department of Gastroenterology, Izmir Atatürk Training and Research Hospital, Izmir, Turkey \\ 2Department of Gastroenterology, Turkiye Yuksek Ihtisas Training and Research Hospital, Ankara, Turkey
}

Prz Gastroenterol 2013; 8 (1): 44-49

DOI: $10.5114 / p g .2013 .34182$

Key words: endoscopy, video information, anxiety, patient satisfaction.

\begin{abstract}
Address for correspondence: Mahmut Arabul MD, Department of Gastroenterology, Izmir Ataturk Training and Research Hospital, İzmir Atatürk Eğitim ve Araștırma Hastanesi, 35160, Karabağlar, İzmir, Turkey, phone: +90 23224444 44, +90 5054976032 , e-mail: mahmutarabul@gmail.com
\end{abstract}

\begin{abstract}
Introduction: Anxiety and stress are common problems in patients undergoing invasive medical procedures. Anxiety before upper gastrointestinal endoscopy may have adverse consequences and can sometimes hamper successful completion of the procedure.

Aim: To investigate the effects of adding an information video or detailed verbal information to our usual preprocedural information.

Material and methods: Four hundred and forty gastrointestinal endoscopy patients were randomly assigned to video (226) or verbal information (214) groups. Patients in the video group watched a 10-minute-long video about the necessity of the endoscopic procedure, doctor and patient cooperation, and possible complications, emphasizing the possible feelings the patients might experience. The patients' situational anxiety was measured using the State-Trait Anxiety Inventory's two scales (STAI-State and STAI-Trait). Patients rated pain and overall satisfaction related to the procedure.

Results: There was a significant difference between the patient groups after endoscopy, in favor of the video group, when the answers to the STAI-S questions "the procedure was similar to what was explained" and "it was worse than what was explained" were evaluated ( $p=0.003, p<0.001$ and $p<0.001$, respectively).

Conclusions: It can be concluded that information by video helps reduce the anxiety of the patient, increases patient satisfaction and the patient is much more readily convinced to undergo another procedure, in cases where a control is needed.
\end{abstract}

\section{Introduction}

Anxiety is a common problem in patients who have to undergo an invasive medical procedure [1]. The increase in stress, and decrease in tolerance, lead to unexpected changes in physiological status, to an increased need for medication postoperatively, to a lower compliance in treatment and to an increase in medical procedures during follow-up [2-4]. Cognitive and behavioral education are used to decrease the stress in patients scheduled for medical procedures. Cognitive techniques are used by way of informing the patients. Patients are basically preoperatively informed with two different approaches. In one approach patients are informed about the procedure and the possible experiences they might have during its course. The second approach focuses on information about the feelings, such as perception and olfactory, auditory and tactile sensations they might experience during the procedure. It has been established that the informative approach, focusing upon feelings, is much more effective than just focusing on the procedure itself during endoscopy, colonoscopy and gynecologic examination [5-9].

Endoscopic procedures can be painful and uncomfortable and patient cooperation is very important for a successful result. This anxiety can hamper a successful result of the procedures [5]. In routine practice, ver- 
bal or written communication is used to inform the patient. Mostly this information is focused on the procedure itself and its complications, and it is a fact that most of the time management of the patient's feelings and optimizing the expectations are subjects that are neglected. Also, most of the patients do not read the written information, or else they do not understand it. On the other hand, verbal information is usually given just before the procedure, when the patient is already anxious and experiencing stress and emotional chaos, and it is hard for the patient to control emotions in that state. There are different studies investigating the appropriate informative approach before endoscopic procedures, in order to optimize patient comfort and procedure quality [6, 10-13]

\section{Aim}

In our study, we aimed to compare the effect of showing an informative video or providing verbal group education before the procedure, in addition to informed consent, on the State-Trait Anxiety Inventory's two scales (STAI-State and STAI-Trait) and on communication success and patient satisfaction in patients scheduled for endoscopy. We also aimed to evaluate the effect of gender on patient satisfaction and communication success.

\section{Material and methods \\ Patients}

The study was carried out in our tertiary reference center (Izmir Ataturk Training and Research Hospital, Department of Gastroenterology) between October 2010 and January 2011. All patients included in the study were aged 18-70 and at least primary school graduates. We did not administer any medicine for sedation before or during the procedure. Patients who could not speak Turkish were not included. Approval was obtained from the local ethics committee. All patients signed informed consent.

\section{Study design}

A written form containing information about the procedure and its complications was given to all of the patients who were scheduled for endoscopy. An endoscopy appointment was made for approximately 3-4 weeks later. On the procedure day, about $1-5 \mathrm{~h}$ before the procedure, the patients were taken randomly in groups of 5, and appointed to the video or verbal group, to be included in the study. The verbal and video information and also filling out of the questionnaire were all conducted by medical doctors not attending the endoscopic procedure. In the video group, we showed an approximately 10-minute-long video that we had prepared, providing information such as: the necessity of the endoscopic procedure; doctor and patient cooperation during the procedure; the scope and setting used during the procedure; the possible complications emphasizing the possible feelings the patients might experience; and things that must be done by the doctor and patient in order to avoid excessive nausea, vomiting, retching, distention, etc., which would pass when the procedure was over. Following the video, patients' questions were answered. In the verbal group, the same information that the video included was explained to the patients verbally by a medical doctor not attending the endoscopic procedure and questions were answered again at the end. A questionnaire was filled out for information regarding the patients' age, gender, weight, height, educational status, occupation, concomitant diseases, drugs used, complaints that brought them to an endoscopic procedure, history of a minor or major operation, delivery, traffic accident, tooth extraction, history of any previous endoscopy or colonoscopy, and history of having heard about other people's experience regarding endoscopy or colonoscopy. Also, the questions of the State-Trait Anxiety Inventory's two scales (STAI-State and STAI-Trait) were requested to be answered. In approximately 1-5 $\mathrm{h}$, the patients were taken for endoscopy, without sedation or anesthesia, performed by experienced doctors who were not present in the meeting room and did not have any knowledge about the answers.

\section{Outcome assessments}

As all of the questions, except those about name, age, weight, height, drugs used and occupation, were prepared to be answered by placing an " $x$ " in small boxes, the questionnaire was evaluated quite clearly.

STAI-State (STAI-S) and STAI-Trait (STAI-T) are two different pen and pencil tests, answered by the individual. One of the scales used in the study, STAI-S, evaluates how the person feels within the conditions he/she is in at the present moment, and the other one, STAI-T, evaluates how the individual feels in general. The scale was developed by Spielberger CD [14]. STAI-S and STAI-T comprise 20 questions each, and are answered as "none", "a little", "a lot", and "totally". STAI-S and STAI-T receive scores between 20 and 80 , and higher scores are correlated with the severity of anxiety.

The questions "Would you be prepared to have another procedure for your own health?" and "Was the procedure worse or better than it was explained to be?" were asked to the patients following the procedure. If the patient answered that it was as explained or better, communication was accepted as successful and the 
Table I. Demographic and clinical characteristics of patients at study entry

\begin{tabular}{lccc} 
Parameter & Video group $(n=226)$ & Verbal group $(n=214)$ & Value of $p$ \\
\hline Age [year] & $46.6 \pm 13.2$ & $44.3 \pm 11.7$ & NS \\
\hline Gender (male/female) & $94 / 132$ & $92 / 122$ & NS \\
\hline Body mass index $\left[\mathrm{kg} / \mathrm{m}^{2}\right]$ & $27.1 \pm 11.0$ & $26.5 \pm 5.0$ & NS \\
\hline $\begin{array}{l}\text { Educational status: } \\
\text { Primary education }\end{array}$ & 135 & 158 & NS \\
\hline High school & 62 & 37 & NS \\
\hline University & 19 & 19 & NS
\end{tabular}

NS: $p<0.05$

patient as happy. The others were accepted to be unsuccessful. The question "What was the most annoying complaint during the procedure?" was also asked. And lastly, the endoscopic diagnoses were written under the questionnaire.

\section{Statistical analysis}

Mann-Whitney U-test and independent samples $T$-test were performed according to data distribution for comparison between two independent groups. Pearson $\chi^{2}$ test and Fisher's exact test were used for categorical variables. The impacts of variables on process success were assessed using univariate and multiple logistic regression analyses. Mean and standard deviation were indicated together. The limit of significance was accepted as $p<0.05$. Statistical calculations were performed using SPSS 13.0 (Chicago, IL, USA).

\section{Results}

A total of 440 patients were evaluated in the study. 186 were male, 254 female. Patients were divided into

Table II. Gastrointestinal endoscopy indications of study participants

\begin{tabular}{lccc} 
Parameter & $\begin{array}{c}\text { Video group } \\
(n=226)\end{array}$ & $\begin{array}{c}\text { Verbal group } \\
(n=214)\end{array}$ & Value of $p$ \\
\hline Dyspepsia & 141 & 142 & NS \\
\hline Heartburn & 41 & 51 & NS \\
\hline Bloated feeling & 136 & 125 & NS \\
\hline Early satiety & 28 & 16 & NS \\
\hline Weight loss & 24 & 23 & NS \\
\hline Emesis/vomiting & 53 & 38 & NS \\
\hline Odynophagia & 14 & 21 & NS \\
\hline Others & 8 & 15 & NS
\end{tabular}

$N S: p<0.05$ two groups, video and verbal. There was no difference between groups in terms of age, gender, body mass index (BMI), concomitant chronic disease, educational status, medical history of previous endoscopic and colonoscopic procedures, and having heard about other people's experience regarding endoscopic procedures (Table I). No difference was found, either, between the two groups of patients in terms of the disease requiring the endoscopic procedure (Table II).

There was a significant difference between groups in favor of the video group, when answers to STAI-S, to the questions "The procedure was similar to what was explained" and "It was worse than explained", were evaluated after endoscopy $(p=0.003, p<0.001$ and $p<0.001$, respectively). There was no difference between groups regarding endoscopic diagnoses and procedural complaints (Table III). When evaluated for gender, we found that STAI-S and STAI-T were higher in females $(p<0.001$ and $p<0.001$, respectively) (Table IV).

If the patients stated that the procedure was similar or better than what was explained, the communication was accepted to be successful and the patient satisfied. In the univariate and multivariate logistic regression analysis, it was found that low STAI-S levels $(p<0.001$ and $p<0.001$, respectively), communication by video $(p<0.001, p<0.001$, respectively) and age $(p<0.001$ and $p<0.013$, respectively) significantly affect communication success. We also found with multivariate analysis that having undergone a previous endoscopy or colonoscopy affects communication success $(p=0.035)$ (Table V).

\section{Discussion}

High anxiety levels before medical or surgical interventions can lead to some undesirable results. The increase in sympathetic discharge and increase in catecholamines and corticosteroids can be very unpleasant 
Table III. Procedure-related outcomes according to video/verbal group

\begin{tabular}{|c|c|c|c|}
\hline Variables & Video group $(n=226)$ & Verbal group $(n=214)$ & Value of $p$ \\
\hline \multicolumn{4}{|l|}{ Endoscopy group: } \\
\hline STAI-State & $37.3 \pm 10.0$ & $46.0 \pm 9.09$ & 0.003 \\
\hline STAI-Trait & $46.5 \pm 8.08$ & $45.9 \pm 7.45$ & NS \\
\hline Similar to explanation & 161 & 108 & $<0.001$ \\
\hline Better than explanation & 46 & 42 & NS \\
\hline Worse than explanation & 23 & 64 & $<0.001$ \\
\hline Would do again (for health) (yes/no) & $211 / 15$ & $193 / 21$ & NS \\
\hline \multicolumn{4}{|l|}{ Diagnosis: } \\
\hline Normal & 87 & 74 & \\
\hline Esophageal & 22 & 31 & NS \\
\hline Gastric & 109 & 93 & \\
\hline Duodenal & 8 & 16 & \\
\hline \multicolumn{4}{|l|}{ Complaints (procedural): } \\
\hline Retching & 118 & 116 & \\
\hline Like choke & 15 & 10 & NS \\
\hline Like tear & 0 & 1 & \\
\hline Abdominal pain & 8 & 7 & \\
\hline
\end{tabular}

STAI - State-Trait Anxiety Inventory scale, NS: $p<0.05$

Table IV. Outcomes according to sex of patients

\begin{tabular}{|c|c|c|c|}
\hline Variables & Male $(n=186)$ & Female $(n=254)$ & Value of $p$ \\
\hline STAI-S & $38.6 \pm 9.71$ & $45.8 \pm 9.04$ & $<0.001$ \\
\hline STAI-T & $42.3 \pm 6.84$ & $47.6 \pm 8.13$ & $<0.001$ \\
\hline \multicolumn{4}{|c|}{ What do you think after endoscopy? } \\
\hline Similar to explanation & 118 & 151 & NS \\
\hline Better than explanation & 36 & 52 & NS \\
\hline Worse than explanation & 35 & 52 & NS \\
\hline
\end{tabular}

STAl - State-Trait Anxiety Inventory scale, NS: $p<0.05$

for the patient $[15,16]$. The need for an anesthetic agent may increase as well, if it is to be used [17]. It has been reported that the information provided visually during cardiac catheterization in coronary artery surgery, thalassemia, and COPD affects patient compliance and treatment results positively [18-22].

There are two main goals that have to be achieved by information before medical and surgical procedures: one is to inform about the disease, the procedure to be performed, and the postoperative possibilities; and the other is to reduce the situational anxiety [23-25]. In order to achieve these goals, the interaction between situational anxiety, memory regarding fear and the association with past knowledge has to be well understood. Although mild anxiety can be healed with the motivator's efforts, the situation is much more complicated and difficult in severe anxiety [26].
The individual differences in coping with the stress caused by procedures can be the reason for the difference in the efficacy of preoperative information. While some patients do want to be informed, others may avoid the information [27]. The ideal approach in preoperative information is not clear yet. Traditionally, this information is provided verbally by the clinician. During the verbal interaction between doctor and patient, the difference in intellectuality and terminology prevents goal achievement. There are some studies about the video method in patients scheduled for colonoscopy, with the aim of creating a standard and optimizing patient information [6,7]; there also are studies that report on the increase in anxiety during upper gastrointestinal endoscopy [28] and those that have investigated the effects of verbal information [29], but we did not encounter a study in the literature 
Table V. Univariate and multivariate analysis of procedure-related outcomes according to the success of communication

\begin{tabular}{lccc} 
Variables & $\begin{array}{c}\text { Odds ratio }(95 \% \mathrm{Cl}) \\
\text { (univariate analysis) }\end{array}$ & $\begin{array}{c}\text { Odds ratio }(95 \% \mathrm{Cl}) \\
\text { (multivariate analysis) }\end{array}$ & Value of $p$ \\
\hline Age & $0.968(0.950-0.987)$ & $0.967(0.941-0.993)$ & 0.001 \\
\hline Gender & $1.111(0.689-1.790)$ & $0.767(0.428-1.377)$ & NS \\
\hline Educational status & $1.225(0.878-1.709)$ & $1.066(0.681-1.668)$ & NS \\
\hline BMI & $0.965(0.920-1.011)$ & $0.980(0.933-1.029)$ & NS \\
\hline Video/verbal & $3.776(2.236-6.341)$ & $3.997(2.212-7.220)$ & $<0.001$ \\
\hline STAl-State & $1.050(1.023-1.078)$ & $1.063(1.027-1.100)$ & $<0.001$ \\
\hline STAI-Trait & $1.013(0.983-1.044)$ & $0.993(0.952-1.035)$ & NS \\
\hline Additional chronic disease & $1.294(0.792-2.113)$ & $1.490(0.806-2.753)$ & NS \\
\hline Did the patients hear bad endoscopic hearsay? & $1.112(0.679-1.819)$ & $0.952(0.538-1.685)$ & NS \\
\hline Regional diagnosis & $0.960(0.824-1.118)$ & $0.959(0.803-1.145)$ & NS \\
\hline Before endoscopy or colonoscopy & $1.431(0.849-2.412)$ & $1.962(1.048-3.673)$ & NS
\end{tabular}

BMI - body mass index, STAI - State-Trait Anxiety Inventory scale, $95 \% \mathrm{Cl}-95 \%$ confidence interval. Results expressed as median and inter-quartile $25-75 \%$ interval. Student $t$ test or Mann-Whitney depending on normal distribution, NS: $p<0.05$

that investigates the effect of visual communication on anxiety and procedure success.

In the evaluations of patients who have been satisfied with endoscopic and colonoscopic procedures, it has been shown that doctor-patient cooperation is important [10]. In a study with children and adolescents, it was reported that psychological preparation using photographs reduces anxiety [11]. Again in a study with endoscopy and colonoscopy patients, it was reported that music was successful in affecting the auditory perceptions of the patients [12]. In a study performed by Lanius et al. [13], it was reported that informing the patient with a pamphlet before an endoscopic or colonoscopic procedure does not provide a decrease in the anxiety, and that information should be individualized [13]. In our study, the situational anxiety (STAI-S) decreased significantly in the group informed by video; we also found a significant superiority in favor of the video group when we evaluated the questions aimed at establishing patient satisfaction (Table IV). The result of our univariate and multivariate analysis regarding communication success showed that situational anxiety is significantly affected by visual communication and age. There are studies about the effect of age on communication success (patient satisfaction) [29]. Also, our result showing that the STAI-S and STAI-T levels are significantly higher in females compared to males is similar to the literature $[6,31]$.

It can be concluded from the results of our study that information provided by video helps reduce the anxiety of the patient and increases patient satisfaction, and that the patient is much more readily convinced to undergo another procedure in cases where a control is needed. One of the other results of our study is that dif- ferent strategies should be followed for information in different genders. The effect of visual information on long-term anxiety, patient satisfaction and procedure success in patients scheduled for endoscopy is a topic deserving investigation.

\section{References}

1. Weinman J, Johnston M. In: Topics in health psychology. Maes S, Spielberger CD, Defares P, Sarason I (eds.). John Wiley \& Sons, Chichester 1988.

2. Williams JGL, Jones JR, Workhoven MN, Williams B. The psychological control of preoperative anxiety. Psychophysiology 1975; 12: 50-4

3. Genzdilov AV, Alexandrin GP, Simonov NN, et al. The role of stress factors in the postoperative course of patients with rectal cancer. J Surg Oncol 1977; 9: 517-23.

4. Sime AM. Relationship of preoperative fear, type of coping and information received about surgery to recovery from surgery. J Pers Soc Psychol 1976; 34: 716-24.

5. Johnson JE, Morrisey JF, Leventhal H. Psychological preparation for an endoscopic examination. Gastrointest Endosc 1973; 19: 180-2.

6. Luck A, Pearson S, Maddern G, et al. Effect of video information on precolonoscopy and knowledge; a randomised trial. Lancet 1999; 354: 2032-5.

7. Agre P, Kurtz RC, Krauss BJ. A randomize trial using videotape to present consent information for colonoscopy. Gastrointest Endosc 1994; 40: 271-6.

8. Shipley RH, Butt JH, Farbry J, Horwitz B. Psychological preparation for endoscopy. Physiological and behavioral changes in patients with differing coping styles for stress. Gastrointest Endosc 1977; 24: 9-13.

9. Fuller SS, Endress MP, Johnson JE. The effects of cognitive and behavioral control on coping with an aversive health examination. J Human Stress 1978; 4: 18-25. 
10. Mahajan RJ, Johnson JC, Marshall JB. Predictors of patient cooperation during gastrointestinal endoscopy. J Clin Gastroenterol 1997; 24: 220-3.

11. Mahajan L, Wyllie R, Steffen R, et al. The effects of psychological preparation program on anxiety in children and adolescents undergoing gastrointestinal endoscopy. J Pediatr Gastroenterol Nutr 1998; 27: 161-5.

12. Felley C, Perneger TV, Goulet I, et al. Combined written and oral information prior to gastrointestinal endoscopy compared with oral information alone: a randomized trial. BMC Gastroenterol 2008; 8: 22.

13. Lanius M, Zimmermann P, Heegewaldt $H$, et al. Does an information booklet on gastrointestinal endoscopy reduce anxiety for these examinations? Results of a randomized study with 379 patients. Z Gastroenterol 1990; 28: 651-5.

14. Spielberg CD. Manual for state-trait anxiety inventory. Consulting Psychologists Press, California 1970.

15. Williams QA. Patient knowledge of operative care. J R Soc Med 1993; 86: 328-31.

16. Fell D, Derbyshire DR, Maile CJD, et al. Measurement of plasma catecholamine concentrations: an assessment of anxiety. $\mathrm{Br}$ J Anaesth 1985; 57: 770-4.

17. Goldmann I, Ogg TW, Levey AB. Hypnosis and daycase anaesthesia: a study to reduce pre-operative anxiety and intraoperative anaesthetic requirements. Anaesthesia 1988; 43: 466-9.

18. Kulik JA, Mahler HIM. Effects of preoperative roommate assignment on preoperative anxiety and recovery from coronarybypass surgery. Health Psychol 1987; 6: 525-43.

19. Black I, Mitchell M. Evaluation of a patient education program for chronic obstructive pulmonary disease. Mayo Clin Proc 1997; 52: 106-11.

20. Fisher I, Rowley PT, Lipkin M. Genetic counselling for beta-thalassaemia trait following health screening in a Health Maintenance Organisation: comparison of programmed and conventional counselling. Am J Hum Genet 1981; 33: 987-94.

21. Uzark K, Klos D, Davis W, Rosenthal A. Use of videotape in the preparation of children for cardiac catheterisation. Pediatr Cardiol 1982; 3: 287-91.

22. Herrmann KS, Kreuzer $\mathrm{H}$. A randomized prospective study on anxiety reduction by preparatory disclosure with and without video film show about a planned heart catheterization. Eur Heart J 1989; 10: 753-7.

23. Cassileth BR, Zupkis RV, Sutton-Smith K, March V. Informed consent: why are its goals imperfectly realised? N Engl J Med 1980; 302: 896-900.

24. Johnston M, Vogele C. Benefits of psychological preparation for surgery: a meta-analysis. Ann Behav Med 1993; 15: 245-56.

25. Marteau TM, Kidd J, Cuddeford L. Reducing anxiety in women referred for colonoscopy using an information booklet. $\mathrm{Br}$ J Health Psychol 1996; 1: 181-9.

26. McEwen B, Sapolsky R. Stress and cognitive function. Curr Opin Neurobiol 1995; 5: 205-16.

27. Miller SM, Mangan CE. Interacting effects of information and coping in adapting to gynaecological stress: should the doctor tell all? J Pers Soc Psychol 1983; 45: 223-36.

28. Jones MP, Ebert CC, Sloan T, et al. Patient anxiety and elective gastrointestinal endoscopy. J Clin Gastroenterol 2004; 32 69-75.
29. Bechtold ML, Puli SR, Othman MO, et al. Effect of music on patients undergoing colonoscopy: a meta-analysis of randomized controlled trials. Dig Dis Sci 2009; 54: 19-24.

30. Takahashi Y, Tanaka H, Kinjo M, Sakumoto K. Prospective evaluation factors predicting difficulty and pain during sedationfree colonoscopy. Dis Colon Rectum 2005; 48: 1295-300.

31. Bytzer P, Lindeberg B. Impact of an information video before colonoscopy on patient satisfaction and anxiety - a randomized trial. Endoscopy 2007; 39: 710-4. 